\title{
Usability issues in mobile learning: Students' perceptions in Pakistani universities
}

\author{
Umera Imtinan \\ School of Information Systems, Curtin \\ University \\ Umera_imtinan@yahoo.com
}

\author{
Vanessa Chang \\ School of Information Systems, Curtin \\ University \\ Vanessa.chang@curtin.edu.au
}

\author{
Tomayess Issa \\ School of Information Systems, Curtin University \\ Tomayess.issa@cbs.curtin.edu.au
}

\begin{abstract}
Usability in mobile devices, for learning, has drawn researchers' attention since the term mobile learning has been coined in teaching and learning arenas. Current mobile devices in the market have ignored the design and styles for learning purposes. Although mobile devices have some features for games purposes, there are other important usability characteristics that ought to be considered to support learning. Therefore, mobile learning researchers need to investigate the learning options with the available capabilities of mobile devices. Students in developing countries reported more problems related to usability based on their individual experiences dealing with mobile devices for learning purposes. This paper aims to identify the implications of usability in mobile devices for learning based on research conducted in Pakistan.
\end{abstract}

\section{Author Keywords \\ Mobile learning, usability, usability of mobile devices, perceptions, university students, developing countries}

\section{INTRODUCTION}

Usability relates to the ease of using mobile devices for learning purposes in respect to screen size, battery life, physical size, weight, memory, processing power, compatible applications and user interface (Koole, 2009; Kukulska-Hulme, 2005). In the case of mobile devices for learning, Koole (2009) includes a number of other factors such as the aesthetic appeal of the device, simplified display, fewer steps required to perform a task, ease of navigation, customization options and environment or climate of the place where the learner is located.

Besides the usability features of mobile devices, Kuen (2006) provides a usability guidelines framework for designing mobile learning portals, which focus on analysing the learner's usage skills, human-mobile interaction and interface design as main categories to develop usability guidelines for designing mobile learning portals containing mobile learning content and applications. Bearing in mind the fact that current mobile devices and the ones used in previous pilot projects such as PDAs and smart phones, are not built for learning purposes, it is more likely that learners will face usability problems. Therefore, researchers such as Kuen (2006) recommended a set of guidelines for designers of mobile learning portals. However, as the mobile devices are becoming multi-purpose and more sophisticated in design and functionality, the basic usability problems such as battery life, memory capabilities and screen size limitations, will diminish (Wu et al., 2012).

\section{RESEARCH METHOD, QUESTIONS AND PARTICIPANTS}

Case study research method was chosen as the research approach for this study. Qualitative research techniques were used to collect data. Students from three Pakistani universities were invited to participate in focus groups to discuss mobile learning characteristics for Pakistani universities. This research uses focus group as a qualitative research technique as the opinions of users are paramount for this study. As recommended by Krueger \& Casey (2000) and Morgan, (1997), themes are provided to the participants to guide the discussion of the focus groups. . (Krueger \& Casey, 2000; Morgan, 1997). As such, usability issues for mobile learning characteristics for university environments in Pakistan formed the discussion for the focus group. The main research question for this study was 'how do students perceive usability of mobile devices for learning in the Pakistani university environments?'

The participants were undergraduate students from Computer Science, Telecommunication and Electrical Engineering and Medical backgrounds. In this study, a total of 27 students participated in three focus group discussion sessions conducted in three universities in Pakistan.

\section{DISCUSSION AND FINDINGS}

During the student focus group sessions, it was found that some of the students were not aware of the concept of usability. They knew very little about usability of mobile devices; however, they experienced the issues related to usability of mobile devices for learning without labelling these 'usability issues.' When it was explained to them about usability of mobile devices with reference to their learning, they gave reasonable responses based on their individual experiences. However, there were mixed responses in terms of usability-related issues. Some of them were very happy and reported that they did not face any usability-related problems, unless they were using a new device; these few students seemed to be very experienced users of smart phones. On the other hand, many students reported that they faced 
quite a lot of usability- related issues when they performed learning activities using mobile devices. Some of the comments were as follows:

'I face a little bit of discomfort in viewing something on my mobile device because its viewing area is very narrow that makes scrolling very difficult. Further, typing on a mobile device is very difficult because of tiny keypad.' [Uni A-Student1]

A number of usability-related issues mentioned by these students in the focus groups were quite similar to what is already revealed in the literature, including smaller screen size, rapid battery consumption, smaller memory and storage capabilities, difficulty of attaching large files, not being able to perform tasks requiring heavy processing, some tasks taking more time and more steps, smaller keypad and at times compromised mobile internet speed (Chen, Chen, Hwang, \& Yang, 2010; Kiili, 2002; Kukulska-Hulme, 2005; Uther, 2002; Wei, Zhuo, \& Zhang, 2008).

To summarize common usability issues discussed by the participants of the focus groups, the usability tree in Figure 1 shows the usability node and associated child nodes as outcome from the analysis of the focus groups' interview sessions with Pakistani university students. It is important to note that these are also some of the common usability issues found in mobile learning literature (Chen, et al., 2010; Churchill \& Hedberg, 2008; Daniel Su Kuen, 2006; Kukulska-Hulme, 2005). Results of this study confirmed what has been reported in literature in terms of common mobile device usability issues for learning purposes. Issues related to the usability of mobile devices for learning has been sub-categorised as user interface, battery capabilities, memory and storage.

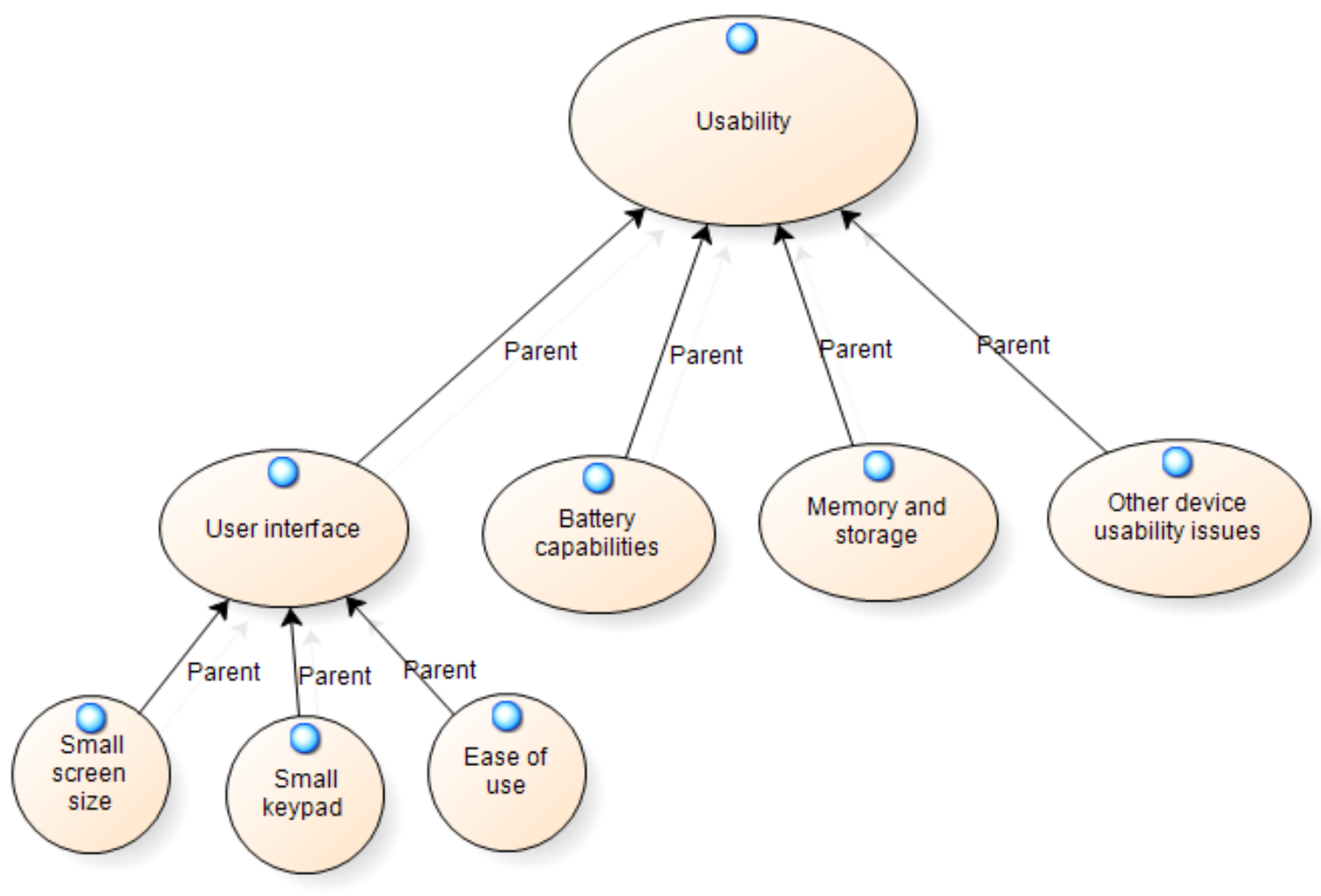

Figure 1: Usability Tree: Common Mobile Device Usability Issues

While moderating the focus groups' sessions, it was observed that there were certain types of students who were technology enthusiasts (generally telecommunication engineering and computer science students) who appeared to have fewer problems when using mobile devices for learning purposes. If they encountered problems, they would find solutions on their own. These students have good IT and software background thus giving them the ability to troubleshoot issues and problems with their mobile devices. Generally, these students can also afford expensive smart phones enabling them to explore more features and experience better usability of mobile devices in general use and for mobile learning.

Koole (2009) discussed user experience as a big factor in reference to the usability issues of a mobile device when used for learning; the more users are experienced, the less usability issues they would face. Technology enthusiast students were very experienced mobile device users and would probably not require much training if there were formal mobile learning pilot projects in the future. However, students from relatively underprivileged backgrounds were very excited at 
the idea of mobile learning; and these students did not own or experience functionalities of smart phones. Oliver and Goerke (2008) also found similar enthusiasm among Ethiopian students in the use of mobile devices for learning.

In spite of their enthusiasm and motivation, many students reported a number of usability problems such as a small amount of memory, low processing speed and configuration issues. Similar usability issues were also reported by the research conducted by Economides and Grousopoulou (2009). It was also observed that the students who have reported usability problems did not possess modern smart phones and they have found usability problems due to the older technology-oriented phones that they were using. Generally, these studies have classified smart phones as "WiFi Enabled mobile devices" and this showed that many of them did not have a mobile device that was capable of connecting to freely available Wi-Fi and internet provided by the university. Some of the students explicitly mentioned that they did not have a better device and restricted them to perform learning activities on the computer:

'There are some mobile devices like Blackberry, which have big screen, and you can read easily but on other mobile devices, you have to scroll. Now I don't have Blackberry, to so I have to scroll for reading. In spite of all this, we cannot read as easily as we do on a desktop computer.' [Uni C-Student4]

During the analysis of the reported usability issues, it was found that due to a lack of awareness and appropriate training, some students tried to accomplish activities that were not meant to be done on mobile devices and as such they have reported these issues inaccurately as mobile device usability problems. Some of the activities that they tried to perform were code writing for website development, writing special characters in programming assignments or playing games with heavy graphics. :

'I am working as a website development project now-a-day. I don't have internet access at home; therefore, I search on mobile. However, if I have to download some template or have to view some script in php or html, then it becomes difficult to understand on mobile. Some mobiles don't support MS Office. If you have some slides to view, you cannot do that because you can only view pdf files.' [Uni B-Student5]

In this case, the student might be trained and informed that mobile learning is not to replace computer usage in educational environments, particularly for practical courses such as computer programming or engineering.

\section{Summary of Findings}

To answer the research question on 'how do students perceive usability of mobile devices for learning in the Pakistani university environments', from the focus groups discussions, the findings are as follows:

1. Usability related issues such as memory and battery capabilities, tiny keypad and small-screen size are common usability problems. This finding is similar to outcomes of earlier research found in the literature (Chen, et al., 2010; Kiili, 2002; Kukulska-Hulme, 2005; Uther, 2002; Wei, et al., 2008).

2. Technology-savvy students found fewer usability problems in their informal mobile learning activities as they tend to be more experienced users.

3. Students who did not possess smart phones reported more usability issues.

4. Students who did not possess smart phones expressed more excitement and enthusiasm to be involved in mobile learning; Oliver and Goerke (2008) also found similar excitement and determination in African students as compared to Australian students.

5. Students who tried to do complicated, practical and lengthy learning tasks or assignments on the mobile devices without appropriate training or guidance perceived that using a mobile device is more difficult to complete the task.

6. Students needed to be informed and trained appropriately for mobile learning tasks and not all learning activities can be completed using a mobile device efficiently and effectively.

\section{CONCLUSION AND FUTURE RESEARCH}

Usability of mobile devices for learning has been investigated by several researchers since early 2000s. Students from developing countries have certain perceptions about usability of mobile devices for learning, based on their individual user experiences. Students exposed to smart phones seem more technology savvy and experienced users have fewer usability issues. Students with lesser exposure were found to be more enthusiastic for mobile learning engagement. Students need appropriate training for any possible experiment of mobile learning in Pakistani universities. Future research directions include investigating the usability of mobile devices for certain types of learning activities; and this would include investigating the different types of learning materials such as theory-based courses as well as subjects involving practical, lab work, experiments or field work.

\section{ACKNOWLEDGEMENT}

The usability perception study forms a part of a PhD research by the first author. A mobile learning conceptual model with usability as one of the key mobile learning characteristics is expected to be released in 2014. 


\section{REFERENCES}

Chen, C.-H., Chen, S.-H., Hwang, G.-J., \& Yang, T.-C. (2010). Factors influencing teachers\&\#39; adoption of a ubiquitous technology application in supporting teacher performance. International Journal of Mobile Learning and Organisation, 4(1), 39-54.

Churchill, D., \& Hedberg, J. (2008). Learning object design considerations for small-screen handheld devices. Computers \& Education, 50(3), 881-893. doi: DOI: 10.1016/j.compedu.2006.09.004

Daniel Su Kuen, S. (2006). Usability guidelines for designing mobile learning portals. Paper presented at the Proceedings of the 3rd international conference on Mobile technology, applications I\&amp; systems, Bangkok, Thailand.

Economides, A. A., \& Grousopoulou, A. (2009). Students' thoughts about the importance and costs of their mobile devices' features and services. Telematics and Informatics, 26(1), 57-84.

Kiili, K. (2002). Evaluating WAP Usability: "What Usability?". In M. Milrad, U. Hoppe \& Kinshuk (Eds.). Vaxjo, Sweden: IEEE Computer Society.

Koole, M. L. (2009). A model for framing mobile learning. In M. Ally (Ed.), Mobile learning: transforming the delivery of education and training (pp. 25-47): AU Press Canada.

Krueger, R., \& Casey, M. (2000). Focus Groups: A practical guide for applied research. London: Sage Publications.

Kukulska-Hulme, A. (2005). Mobile usability and user experience. In A. Kukulska-Hulme \& J. Traxler (Eds.), Mobile learning: A handbook for educators and trainers (pp. 46-56). London and New York: RoutledgeFalmer.

Morgan, D. L. (1997). Focus groups as qualitative research (Second Edition ed. Vol. 16). Thousand Oaks, California: SAGE Publications, Inc.

Oliver, B., \& Goerke, V. (2008). Undergraduate students' adoption of handheld devices and Web 2.0 applications to supplement formal learning experiences: Case studies in Australia, Ethiopia and Malaysia. International Journal of Education and Development using ICT, 4(3), 1-14.

Uther, M. (2002). Mobile Internet Usability: What Can 'Mobile Learning' Learn from the Past? In M. Milrad, U. Hoppe \& Kinshuk (Eds.). Vaxjo, Sweden: IEEE Computer Society.

Wei, J., Zhuo, J., \& Zhang, H. (2008). Development of a mobile learning model with usability features for online education. International Journal of Mobile Learning and Organisation, 2(1), 18-35.

Wu, W.-H., Jim Wu, Y.-C., Chen, C.-Y., Kao, H.-Y., Lin, C.-H., \& Huang, S.-H. (2012). Review of trends from mobile learning studies: A meta-analysis. Computers \&amp; Education, 59(2), 817-827. doi: 10.1016/j.compedu.2012.03.016 